Article

\title{
Enhanced Soil Carbon Storage under Agroforestry and Afforestation in Subtropical China
}

Guibin Wang ${ }^{1, \dagger}$, Clive Welham ${ }^{2, \dagger, *}$, Chaonian Feng ${ }^{1}$, Lei Chen ${ }^{1, \dagger, *}$ and Fuliang Cao ${ }^{1}$

1 Co-Innovation Center for Sustainable Forestry in Southern China, Nanjing Forestry University, Nanjing 210037, China; E-Mails: gbwang@njfu.edu.cn (G.W.); fcn@njfu.com.cn (C.F.); njfu_caofuliang@163.com (F.C.)

2 Department of Forest Resources Management, University of British Columbia, Vancouver, BC V6T 1Z4, Canada

$\dagger$ These authors contributed equally to this work.

* Authors to whom correspondence should be addressed; E-Mails: clive.welham@ubc.ca (C.W.); footchen@126.com (L.C.); Tel.: +1-604-822-8958 (C.W.); Fax: +1-604-822-9106 (C.W.).

Academic Editors: P. K. Ramachandran Nair and Eric J. Jokela

Received: 20 March 2015 / Accepted: 23 June 2015 / Published: 1 July 2015

\begin{abstract}
Soil carbon (C) in three Ginkgo (Ginkgo biloba L.) agroforestry systems, afforestation (Ginkgo alone; G), and an agricultural cropping system were compared over a five-year period. The agroforestry systems were Ginkgo + Wheat (Triticum aestivum L.) + Peanut (Arachis hypogaea L.; GWP); Ginkgo + Mulberry (Morus alba L.; GM); and Ginkgo + Rapa (Brassica napus L.) + Peanut (GRP). The agricultural system consisted of wheat and peanut (WP). Total soil carbon (TSC), soil organic (SOC) and inorganic carbon (SIC), and the pools of five SOC chemical fractions were measured. TSC and SOC were always lower under WP than the G-based planting systems, and TSC in the latter increased significantly across years in the top $20 \mathrm{~cm}$. Stocks of SIC under WP were significantly greater than the G-based systems, whereas SOC fractions tended to be lower. Most fractions increased across years but not in WP.
\end{abstract}

Keywords: Ginkgo biloba; agroecosystem; agroforestry; afforestation; soil carbon; organic carbon; inorganic carbon; carbon fraction 


\section{Introduction}

At around $400 \mathrm{ppm}$, the atmospheric concentration of carbon dioxide $\left(\mathrm{CO}_{2}\right)$, a major greenhouse gas, is $40 \%$ higher than in preindustrial times [1]. The global soil organic carbon (SOC) stock, however, contains at least twice that amount [2]. Hence, even small changes in soil storage could have a significant impact on the levels of atmospheric $\mathrm{CO}_{2}$ [3].

Land-use and land-use change are estimated to be responsible for at least $11 \%$ of annual anthropogenic $\mathrm{CO}_{2}$ emissions [4]. Soil $\mathrm{C}$ stocks are a result of inputs from litter production, root exudates, and microbial immobilization and turnover, balanced against outputs due to biomass removal, heterotrophic respiration, mass movement, and leaching [5], in conjunction with stabilization processes [2]. Additional factors that influence storage indirectly include precipitation [6], temperature [7], topography [8], and cropping and tillage practices [9]. With the conversion of forestland to agriculture, there can be a marked decline in soil organic C stocks, particularly in surface horizons [10,11]. Increases in stocks have been achieved by converting to tillage systems, and by switching from annual to perennial species (including afforestation and agroforestry; [12]) and from sequential monocultures to rotational cropping [5].

The soil $\mathrm{C}$ pool is composed of inorganic and organic components, though with the exception of arid regions, SOC is more abundant and important in determining the biological properties of soils [13]. SOC can be separated into fractions. The passive or recalcitrant pool is resistant to decomposition and relatively stable over long periods [14]. The labile $\mathrm{C}$ pool is a ready source of energy for microbes and other decomposers, cycles rapidly, and has a short residence time [15]. Labile pools are responsive to land-use change and thus are sensitive indicators of soil quality [16-18]. The dynamics of $\mathrm{C}$ in terms of land use have been studied mainly in temperate regions $[5,10]$. This is significant because in the latter regions, many forests have been cleared for agriculture in an effort to feed expanding human populations. Countries are now beginning to recognize the benefits trees provide, however, in terms of sustainable food production (when combined with cropping systems), improvements in soil quality, enhanced C storage, and wood products [5,19-21].

The $\mathrm{C}$ source and sink potential associated with different land use systems has attracted considerable attention [22,23]. In this respect, restoring SOC stocks (and soil fertility) by converting agricultural land back to forest, along with efforts to identify which SOC fractions are most affected by land use patterns, are of widespread interest [24-26]. Afforestation refers simply to the planting of trees on lands that historically did not contain forest [27]. This activity improves SOC storage when stands are left to grow over many decades [27]. In agroforestry, trees, crops and/or cattle are deliberately grown or raised on the same unit of land, in some form of spatial arrangement or temporal sequence. Agroforestry is implemented on more than a billion hectares of land worldwide [28]. SOC storage can be improved under agroforestry versus pasture and field crops, though not always and quantifying changes in soil $\mathrm{C}$ is thus important to assessing its effectiveness [12]. Differing results may be due multiple factors, including climate, prior land use, species selection, the type of SOC measured [5], and the length of time a given system has been in operation [29].

Here, we compare total soil carbon (TSC), and SOC and inorganic carbon (SIC), and the pools of five SOC chemical fractions, in three Ginkgo agroforestry systems (combinations of wheat Triticum aestivum L., peanut Arachis hypogaea L., mulberry Morus alba L., and rapa Brassica napus L.), along 
with afforestation (Ginkgo alone) and a sequential agricultural cropping system (wheat and peanut). Ginkgo is grown extensively throughout subtropical China for its leaves, flowers, fruit, and timber [30,31]. The other species are important cash and/or food crops. Our hypothesis was that the tree-based systems would enhance organic C storage over the agricultural system. Measurements of soil $\mathrm{C}$ were conducted when stand age in the Ginkgo varied from four to eight years. Our objectives were to determine whether agroforestry and planting Ginkgo alone resulted in improved soil C storage and of what type, whether storage varied by depth, and whether any differences were magnified over the five successive measurement years.

\section{Materials and Methods}

\subsection{Study Site}

The study site was located near Taixing City, Jiangsu Province, China ( $\left.30^{\circ} 59^{\prime} \mathrm{N}, 119^{\circ} 48^{\prime} \mathrm{E}\right)$. It is situated in the north subtropical marine monsoon climate zone with a mean annual precipitation of $1031 \mathrm{~mm}$, mean annual temperature of $14.9^{\circ} \mathrm{C}$, and mean annual relative humidity of $80 \%$. The mean monthly maximum temperature is $2{ }^{\circ} \mathrm{C}$ in January, and $27.6{ }^{\circ} \mathrm{C}$ in July [32]. Jiangsu Province is the main Ginkgo growing region in China, accounting for $20 \%$ of annual total nut yield [30].

\subsection{Experimental Design}

The site is approximately 11 ha in size, flat in topography, at an elevation of $5 \mathrm{~m}$ above sea level. Before planting Ginkgo in 2004, it was farmed as agricultural land for more than a decade and planted with wheat, soybean (Glycine $\max$ (L.) Merr.)., rapa and peanut. Soils are alluvial in origin, deep and well drained. Before the experiment was initiated, soil chemical properties ( $\mathrm{pH}$, organic matter content, total and hydrolysable $\mathrm{N}$, total and available $\mathrm{P}$ and $\mathrm{K}$, respectively) were measured (Table 1). Approximately $60 \mathrm{Mg} \cdot \mathrm{ha}^{-1}$ of farm manure was then applied, after which site preparation was conducted with tractor-drawn tilling equipment. This consisted of mixing the soil and farm manure to a depth of 5-10 cm.

Table 1. Baseline soil information for the experimental site in Taixing, Jiangsu Province, China. Soil samples were collected in the 15 experimental plots at the initiation of the study (March 2004) from depths of 0-20, 20-40, and 40-60 cm. SD is standard deviation $(n=3)$.

\begin{tabular}{ccc}
\hline Parameters & Range & Mean \pm SD \\
\hline $\mathrm{pH}$ & $8.1-8.4$ & $8.2 \pm 0.2$ \\
Organic matter $\left(\mathrm{g} \cdot \mathrm{kg}^{-1}\right)$ & $9.1-9.6$ & $9.4 \pm 0.2$ \\
Total N $\left(\mathrm{g} \cdot \mathrm{kg}^{-1}\right)$ & $0.6-0.7$ & $0.6 \pm 0.0$ \\
Hydrolysable $\mathrm{N}\left(\mathrm{mg} \cdot \mathrm{kg}^{-1}\right)$ & $59.2-67.5$ & $62.4 \pm 4.7$ \\
Total P $\left(\mathrm{g} \cdot \mathrm{kg}^{-1}\right)$ & $0.5-0.6$ & $0.5 \pm 0.0$ \\
Available P $\left(\mathrm{mg} \cdot \mathrm{kg}^{-1}\right)$ & $36.7-45.9$ & $41.2 \pm 4.4$ \\
Total $\mathrm{K}\left(\mathrm{g} \cdot \mathrm{kg}^{-1}\right)$ & $1.0-1.1$ & $1.1 \pm 0.1$ \\
Available $\mathrm{K}\left(\mathrm{mg} \cdot \mathrm{kg}^{-1}\right)$ & $28.6-35.3$ & $31.5 \pm 3.6$ \\
\hline
\end{tabular}


Experimental treatments were arranged in a randomized block design, with each 3.5 ha block split into 5, 0.7-ha plots. Treatments consisted of three Ginkgo-crop (agroforestry) combinations, Ginkgo + Mulberry (GM); Gingko + Wheat + Peanut (GWP); and Gingko + Rapa + Peanut (GRP); as well as Ginkgo alone (afforestation; G), and an agricultural treatment consisting of sequential Wheat + Peanut (WP) crops. Each treatment had three replicates.

All crop species are annuals with the exception of mulberry, a perennial whose leaves are used as food for silkworms. Collectively, they comprise a majority of the cropping systems sown by local farmers. The tree-based systems consisted of four-year-old grafted Ginkgo seedlings planted in March 2004 , at $8 \mathrm{~m} \times 8 \mathrm{~m}$ spacing (156 trees ${ }^{\cdot} \mathrm{ha}^{-1}$ ). Beginning in 2004, wheat and rapa were sown in October of each year and harvested the following May. Peanut was then sown in June and harvested in September. In the Ginkgo-mulberry treatment, two-year-old grafted mulberry seedlings were planted in October 2004 at a spacing of $1 \times 1.5 \mathrm{~m}\left(6667 \mathrm{stems} \cdot \mathrm{ha}^{-1}\right)$, and its leaves harvested each year of the experiment in June and July. Mulberry height was kept to below $1.5 \mathrm{~m}$ by hand pruning; the pruned materials were removed from the site. In the Ginkgo afforestation treatment, volunteer ingress of understory plants was minimal and therefore left untouched. Ginkgo nuts were harvested every year in September and October. Ginkgo leaf or branch litter that dropped on the ground was not removed. Fertilizer (N: $\left.\mathrm{P}_{2} \mathrm{O}_{5}: \mathrm{K}_{2} \mathrm{O} ; 10: 7: 8\right)$ was applied to all plots in April and July of each year, at a rate of $750 \mathrm{~kg} \cdot \mathrm{ha}^{-1}$. The crop residues resulting from the harvest of wheat, peanut and rapa were removed from the field. Following each harvest, sites were ploughed to a depth of 5-10 cm.

\subsection{Sample Protocol}

A total of 15, 0.7-ha plots were established with nine soil samples collected per plot, in April 2008 through 2012, using a soil core sampler (inner diameter $7 \mathrm{~cm}$ ) inserted to a maximum depth of $80 \mathrm{~cm}$. Each of the nine samples was equidistant along a diagonal transect and surface residues were manually removed prior to core insertion. The samples were separated into $20-\mathrm{cm}$ increments, $0-20 \mathrm{~cm}$, 20-40 cm, 40-60 cm, and 60-80 cm below surface. Each of the nine samples at a given depth was mixed and used for all subsequent analyses. Samples were stored in separate plastic bags, transported immediately to the laboratory, air-dried, and passed through a $2 \mathrm{~mm}$ sieve to remove stones and root fragments [32].

\subsection{Sample Analysis}

Bulk density, total soil $\mathrm{C}$, organic and inorganic $\mathrm{C}$, and organic $\mathrm{C}$ fractions (see below) were calculated for each sample. Bulk density was calculated after correction for fragments $>2 \mathrm{~mm}$ by removing a subsample of known volume, which was oven-dried at $60{ }^{\circ} \mathrm{C}$ for at least $24 \mathrm{~h}$ and then weighed. The total soil C (TSC; \%) concentration was determined with a TOC analyzer (ELEMENTAR Analysensysteme GmbH, Hanau, Germany). We used a soil acidification pre-treatment method before measuring soil organic $\mathrm{C}$ content. Soil samples were soaked for $24 \mathrm{~h}$ in $0.3 \mathrm{~mol} \cdot \mathrm{L}^{-1} \mathrm{HCl}$ solution to remove inorganic $\mathrm{C}$. The sample was then flushed with deionized water until the solution $\mathrm{pH}$ exceeded 6 , and oven-dried at $60{ }^{\circ} \mathrm{C}$ (see [33]). We used the TOC analyzer to determine soil organic C (SOC) content. Soil inorganic C (SIC; \%) concentration was estimated by 
subtracting \% SOC from \% TSC. Soil C stocks were calculated from bulk density, land area (ha), soil depth, and the respective soil $\mathrm{C}$ concentrations.

Oxidizable organic C (OOC) is essential to nitrogen, phosphorus, and sulfur mineralization, and is an index of SOC stability [34]. It has been used to indicate changes in organic matter quality in cultivated soils [35]. OOC was determined using a potassium permanganate $\left(\mathrm{KMnO}_{4}\right)$ method [24]. A five-gram sample was placed in a $100 \mathrm{~mL}$ centrifuge tube, to which $25 \mathrm{~mL}$ of $333 \mathrm{mM} \cdot \mathrm{L}^{-1} \mathrm{KMnO}_{4}$ was added. A blank sample containing no soil, and standard samples (see below) were also analyzed in each run. The centrifuge tubes were sealed and tumbled for $1 \mathrm{~h}$ at $12 \mathrm{rpm}$, centrifuged for $5 \mathrm{~min}$ at $2000 \mathrm{rpm}$, and the supernatant diluted to 1:250 parts with deionized water. Absorbance of the diluted samples and standards were read on a split beam spectrophotometer at $565 \mathrm{~nm}$. The change in concentration of $\mathrm{KMnO}_{4}$ was used to estimate the amount of oxidized $\mathrm{C}$, assuming that $1 \mathrm{mM} \mathrm{KMnO}_{4}$ is consumed in the oxidation of $9 \mathrm{mg}$ of $\mathrm{C}$.

Particulate organic C (POC) has a rapid turnover time and can vary with cropping intensity [14]. POC was determined following Chan [15]. A twenty-gram sample was tumbled for $18 \mathrm{~h}$ in $100 \mathrm{~mL}$ of $5 \mathrm{~g} \cdot \mathrm{L}^{-1}$ sodium hexametaphosphate solution, and the suspension passed through a $53 \mathrm{~mm}$ sieve. Material retained on the sieve was rinsed several times with distilled water, and dried at $105{ }^{\circ} \mathrm{C}$. The suspension that passed through the sieve was made up to $250 \mathrm{~mL}$ with distilled water, thoroughly mixed by tumbler, and a $25 \mathrm{~mL}$ aliquot removed and centrifuged at $12,100 \mathrm{rpm}$ for $1 \mathrm{~h}$. C was measured in the supernatant using a TOC analyzer (see above). The residue after centrifuging was returned to the $<53 \mathrm{~mm}$ suspension, dried completely at $105{ }^{\circ} \mathrm{C}$, weighed, ground with a mortar and pestle (to $<0.5 \mathrm{~mm}$ ) and analyzed for $\mathrm{C}$ using the TOC analyzer. Total $\mathrm{C}$ content of the $<53 \mathrm{~mm}$ fraction was calculated after correcting for the amount of sodium hexametaphosphate present in the extractant. POC was calculated as the difference in $\mathrm{C}$ passing through the $53 \mathrm{~mm}$ sieve and that obtained from the corresponding whole soil sample, expressed on an oven-dried whole weight basis.

Light fraction organic C (LOC) has features intermediate between undecomposed and heavily weathered organic matter [36]. It is a driving factor in soil respiration, is strongly linked to nitrogen cycling [37], and thought to play an important role in the formation and stability of soil structure, especially the stabilization of soil macroaggregates $(>250 \mathrm{~mm})$ [38]. Heavy fraction organic C (HOC) is a relatively more stable and high-density organomineral fraction than LOC, with lower $\mathrm{C}$ concentrations [39]. It can be a large soil C pool [40]. HOC and LOC were measured as per the methodology described in [41]. A ten-gram sample was weighed, $40 \mathrm{~mL}$ of NaI solution (density $1.70 \mathrm{~g} \cdot \mathrm{cm}^{-3}$ ) added, and the suspension dispersed for $30 \mathrm{~s}$ using a homogenizer. The mixture was covered and allowed to equilibrate for $48 \mathrm{~h}$ at room temperature. The LOC fraction was removed by vacuum, transferred to a filtration unit, and washed under suction with three successive aliquots of $0.01 \mathrm{M} \mathrm{CaCl}_{2}$, followed by three aliquots of distilled water. After drying overnight (approximately $20 \mathrm{~h}$ at $65{ }^{\circ} \mathrm{C}$ ), the residual material was scraped from the filter paper, weighed, and its $\mathrm{C}$ concentration measured with a TOC analyzer (see above). HOC was estimated by subtracting the LOC concentration from the TSC concentration.

Water extractable organic C (WEOC) is a highly mobile and decomposable soil C source $[42,43]$. WEOC was measured from a 5-g sample of soil that was mixed with deionized water at a soil/solution ratio of 1:5 (w/v), and shaken for $1 \mathrm{~h}$ at $90 \mathrm{rpm}$ [44]. Finally, hot water soluble C (HSOC) is positively correlated with soil microbial biomass, microbial nitrogen, mineralizable $\mathrm{N}$, and total carbohydrates, 
key measures of soil quality $[43,45]$. HSOC was determined by first adding $20 \mathrm{~mL}$ of distilled water to a centrifuge tube along with a 4-g soil sample, which was then left to stand for $16 \mathrm{~h}$, at $80{ }^{\circ} \mathrm{C}$ [45]. Both the WEOC and HSOC samples were passed through a $0.45-\mu \mathrm{m}$ membrane filter, and their respective concentrations measured using a TOC analyzer.

\subsection{Statistical Analysis}

Data are reported as the mean \pm standard deviation (SD), and all tests were performed using the SigmaPlot 11.0 statistical software program (Systat Software Inc., Chicago, IL, USA). A Shapiro-Wilk normality test and an equal variance test were conducted prior to all analyses. It indicated the necessity for a $\log$ transformation of the TSC data from the $80 \mathrm{~cm}$ soil sample; no additional transformations were required. A two way repeated measures ANOVA was then conducted to compare all soil C stocks, with year and planting treatment as main effects, and in the case of TSC, year and soil layer as main effects; the latter was conducted for each planting treatment separately. All analyses included an interaction term. The ANOVA was followed by a multiple comparison analysis using the Holm-Sidak method, a component of the SigmaPlot software package. All statistics were evaluated at a $95 \%$ confidence level.

\section{Results}

\subsection{TSC}

The ANOVA for TSC in the $80 \mathrm{~cm}$ profile showed highly significant planting treatment and year main and interaction effects $(p<0.001$; Table 2). TSC was highest in the GM treatment and lowest in WP in each of the five years $(p<0.05$; Table 3$)$. There was no consistent ordering among the three other treatments. The ANOVA for TSC conducted on each $20-\mathrm{cm}$ layer showed highly significant main (planting treatment and year) and interaction effects to $40 \mathrm{~cm}(p<0.001$; Table 2). At $60-80 \mathrm{~cm}$, only planting treatment $(p<0.001)$ and the interaction $(p=0.02)$ were significant, whereas only planting treatment was significant at $60-80 \mathrm{~cm}(p<0.001$; Table 2$)$. TSC was always significantly lower under WP $(p<0.05)$ than any other planting treatment in all years and soil layers (Table 3 ). There were no consistent differences in TSC for the other planting treatments (Table 3).

Table 2. Two-way repeated measures ANOVA results for planting treatment $(\mathrm{P})$ and year (Y), on total soil $\mathrm{C}\left(\mathrm{t} \cdot \mathrm{ha}^{-1}\right)$ to $80 \mathrm{~cm}$, and at $20 \mathrm{~cm}$ increments. Degrees of freedom for main effects and their interactions were $F_{4,40}$, and $F_{16,40}$, respectively.

\begin{tabular}{cccccc}
\hline Soil layer & $\mathbf{0 - 8 0} \mathbf{~ c m}$ & $\mathbf{0 - 2 0} \mathbf{~ c m}$ & $\mathbf{2 0 - 4 0} \mathbf{~ c m}$ & $\mathbf{4 0 - 6 0} \mathbf{~ c m}$ & $\mathbf{6 0 - 8 0} \mathbf{~ c m}$ \\
\hline \multirow{2}{*}{$\mathrm{P}$} & $F=943.3$ & $F=209.0$ & $F=380.1$ & $F=150.5$ & $F=60.4$ \\
& $p<0.001$ & $p<0.001$ & $P<0.001$ & $p<0.001$ & $p<0.001$ \\
\hline \multirow{2}{*}{$\mathrm{Y}$} & $F=32.9$ & $F=64.7$ & $F=11.5$ & $F=1.1$ & $F=1.3$ \\
& $p<0.001$ & $p<0.001$ & $p<0.001$ & $p=0.382$ & $p=0.279$ \\
\hline \multirow{2}{*}{$\mathrm{P} \times \mathrm{Y}$} & $F=3.7$ & $F=6.2$ & $F=3.1$ & $F=2.2$ & $F=1.5$ \\
& $p<0.001$ & $p<0.001$ & $p=0.002$ & $p=0.020$ & $p=0.167$ \\
\hline
\end{tabular}


Table 3. Mean ( $\pm \mathrm{SD} ; n=3)$ total soil $\mathrm{C}\left(\mathrm{t} \cdot \mathrm{ha}^{-1}\right)$ to $80 \mathrm{~cm}$ and at 20 - $\mathrm{cm}$ layers, for five treatments, Ginkgo + rapa + peanut (GRP); Ginkgo + mulberry (GM); Ginkgo + wheat + peanut (GWP); Ginkgo afforestation (G); and wheat + peanut (WP). The first letters are tests across planting treatment for a given year and soil layer. Letters behind the first comma are tests across soil layer within a given year and planting treatment. Letters behind the second comma are tests across years within a given soil layer and planting treatment. Different letters denote statistically significant differences $(p<0.05)$.

\begin{tabular}{|c|c|c|c|c|c|c|}
\hline \multirow{2}{*}{$\begin{array}{c}\text { Soil } \\
\text { layer }\end{array}$} & \multirow{2}{*}{$\begin{array}{c}\text { Planting } \\
\text { treatment }\end{array}$} & \multicolumn{5}{|c|}{ Year } \\
\hline & & 2008 & 2009 & 2010 & 2011 & 2012 \\
\hline \multirow{5}{*}{$\begin{array}{c}0-80 \\
\mathrm{~cm}\end{array}$} & GRP & $60.5 \pm 1.3 b$ & $61.3 \pm 3.5 c$ & $64.0 \pm 2.8 \mathrm{~b}$ & $68.6 \pm 3.8 c$ & $74.3 \pm 3.5 \mathrm{bc}$ \\
\hline & GM & $78.2 \pm 2.9 a$ & $75.1 \pm 3.5 a$ & $87.4 \pm 4.4 a$ & $90.5 \pm 3.5 a$ & $93.3 \pm 3.8 a$ \\
\hline & GWP & $64.3 \pm 2.7 b$ & $68.32 \pm 2.9 b$ & $65.0 \pm 2.9 b$ & $74.8 \pm 1.7 b$ & $78.9 \pm 3.6 b$ \\
\hline & G & $60.5 \pm 1.1 b$ & $60.4 \pm 3.5 c$ & $65.1 \pm 3.3 b$ & $66.2 \pm 3.8 c$ & $72.4 \pm 1.2 c$ \\
\hline & WP & $34.5 \pm 3.1 c$ & $30.6 \pm 2.9 d$ & $32.9 \pm 2.3 c$ & $34.5 \pm 2.4 d$ & $33.9 \pm 3.4 d$ \\
\hline \multirow{5}{*}{$\begin{array}{c}0-20 \\
\mathrm{~cm}\end{array}$} & GRP & $19.6 \pm 2.0 a, a, a$ & $21.6 \pm 0.5 b c, a, a$ & $26.0 \pm 1.8 b, a, b$ & $28.4 \pm 2.6 b, a, b$ & $32.0 \pm 3.2 b, a, c$ \\
\hline & GM & $22.1 \pm 1.3 a, a, a$ & $26.9 \pm 1.7 a, a, b$ & $32.8 \pm 3.9 a, a, c$ & $34.4 \pm 1.3 a, a, c d$ & $36.4 \pm 1.4 a, a, d$ \\
\hline & GWP & $22.4 \pm 0.9 a, a, a$ & $24.0 \pm 0.4 a b, a, a$ & $27.0 \pm 3.1 b, a, b$ & $32.0 \pm 1.5 a, a, c$ & $37.6 \pm 2.5 a, a, d$ \\
\hline & G & $19.2 \pm 1.2 a, a, a$ & $19.1 \pm 2.0 c, a, b$ & $19.7 \pm 1.7 c, a, a b$ & $24.1 \pm 1.8 c, a, c$ & $29.6 \pm 1.7 b, a, d$ \\
\hline & WP & $14.1 \pm 1.2 b, a, a$ & $12.6 \pm 1.3 d, a, a$ & $14.1 \pm 1.3 d, a, a$ & $14.3 \pm 2.1 d, a, a$ & $14.2 \pm 1.2 c, a, a$ \\
\hline \multirow{5}{*}{$\begin{array}{c}20-40 \\
\mathrm{~cm}\end{array}$} & GRP & $19.5 \pm 0.9 b, a, a$ & $18.2 \pm 1.0 b, b, a$ & $18.7 \pm 1.5 b, b, a$ & $20.4 \pm 0.9 b, b, a$ & $21.5 \pm 1.2 b, b, a$ \\
\hline & GM & $26.9 \pm 1.2 a, b, a b$ & $24.3 \pm 2.0 a, a, b$ & $27.5 \pm 1.0 a, b, a b$ & $27.2 \pm 1.2 a, b, a b$ & $28.7 \pm 1.1 a, b, b$ \\
\hline & GWP & $21.1 \pm 1.1 b, a, a$ & $22.9 \pm 0.8 a, a, a$ & $19.3 \pm 0.9 b, b, a$ & $21.9 \pm 1.3 b, b, a$ & $22.7 \pm 1.4 b, b, a$ \\
\hline & G & $20.3 \pm 0.2 c, b, b$ & $19.9 \pm 1.1 b, a, a$ & $20.9 \pm 0.5 b, a, a$ & $21.6 \pm 0.6 b, b, a b$ & $22.3 \pm 1.0 b, b, a b$ \\
\hline & WP & $11.8 \pm 0.9 d, b, a$ & $8.9 \pm 1.3 c, b, a$ & $10.2 \pm 1.5 c, b, a$ & $11.3 \pm 1.0 c, b, a$ & $11.0 \pm 1.1 c, b, a$ \\
\hline \multirow{5}{*}{$\begin{array}{c}40-60 \\
\mathrm{~cm}\end{array}$} & GRP & $13.5 \pm 1.3 b, b, a$ & $14.1 \pm 4.1 a, c, a$ & $12.1 \pm 1.3 b, c, a$ & $11.7 \pm 1.1 b, c, a$ & $13.4 \pm 0.9 b, c, a$ \\
\hline & $\mathrm{GM}$ & $16.9 \pm 0.8 a, c, a$ & $14.8 \pm 1.3 a, b, a$ & $16.5 \pm 1.1 a, c, a$ & $18.8 \pm 1.6 a, c, a$ & $17.7 \pm 1.3 a, c, a$ \\
\hline & GWP & $11.4 \pm 0.4 b, b, a b$ & $14.2 \pm 1.7 a, b, b$ & $11.1 \pm 0.9 b, c, a b$ & $12.2 \pm 0.9 b, c, a b$ & $10.1 \pm 1.0 \mathrm{~b} c, c, a$ \\
\hline & G & $13.4 \pm 0.6 b, c, a$ & $13.1 \pm 1.0 a, b, a$ & $11.9 \pm 1.4 b, b, a$ & $13.4 \pm 1.5 b, c, a$ & $11.3 \pm 0.7 c, c, a$ \\
\hline & WP & $5.0 \pm 1.6 c, c, a$ & $4.2 \pm 1.1 b, c, a$ & $4.2 \pm 1.1 c, c, a$ & $3.8 \pm 0.8 c, c, a$ & $4.4 \pm 0.9 d, c, a$ \\
\hline \multirow{5}{*}{$\begin{array}{c}60-80 \\
\mathrm{~cm}\end{array}$} & GRP & $7.9 \pm 1.0 b, c, a$ & $7.4 \pm 0.5 b, d, a$ & $7.1 \pm 0.8 b, d, a$ & $8.0 \pm 1.0 b, d, a$ & $7.2 \pm 0.7 b, d, a$ \\
\hline & GM & $12.3 \pm 1.2 a, d, a$ & $9.2 \pm 1.7 a, c, a$ & $10.4 \pm 1.2 a, d, a$ & $9.9 \pm 1.2 a, d, a$ & $10.3 \pm 1.6 a, d, a$ \\
\hline & GWP & $9.4 \pm 1.6 b, b, a$ & $7.2 \pm 1.1 b, c, a$ & $7.6 \pm 1.0 b, d, a$ & $8.6 \pm 1.8 b, d, a$ & $8.3 \pm 0.9 b, c, a$ \\
\hline & G & $7.6 \pm 0.6 b, d, a$ & $8.2 \pm 1.5 b, c, a$ & $7.4 \pm 1.1 b, c, a$ & $6.9 \pm 1.4 b, d, a$ & $9.1 \pm 0.9 b, d, a$ \\
\hline & WP & $3.7 \pm 0.9 c, c, a$ & $4.8 \pm 1.0 c, c, a$ & $4.1 \pm 0.8 c, c, a$ & $5.0 \pm 0.4 c, c, a$ & $4.1 \pm 1.1 c, c, a$ \\
\hline
\end{tabular}

For TSC in the G-based treatments, the layer and year main effects and their interaction were all highly significant ( $p \leq 0.006$; Table 4 ). Only the layer main effect was significant for WP (Table 4). In all planting treatments, there was a significant decline in TSC with soil layer in all years $(p<0.05$; Table 3). For the G-based planting treatments, TSC increased significantly $(p<0.05)$ across years in the surface $(0-20 \mathrm{~cm})$ layer but not in lower layers (Table 3$)$. 
Table 4. Two-way repeated measures ANOVA results for soil layer (L) and year (Y), on total soil $\mathrm{C}\left(\mathrm{t} \cdot \mathrm{ha}^{-1}\right)$. Each planting treatment was analyzed separately. Degrees of freedom for main effects and their interactions were $F_{4,40}$, and $F_{16,40}$, respectively.

\begin{tabular}{cccccc}
\hline & GRP & GWP & GM & G & WP \\
\hline \multirow{2}{*}{$\mathrm{L}$} & $F=205.0$ & $F=1893.2$ & $F=540.8$ & $F=448.3$ & $F=294.9$ \\
& $p<0.001$ & $p<0.001$ & $p<0.001$ & $p<0.001$ & $p<0.001$ \\
\hline \multirow{2}{*}{$\mathrm{Y}$} & $F=9.2$ & $F=22.4$ & $F=11.4$ & $F=8.2$ & $F=0.9$ \\
& $p=0.004$ & $p<0.001$ & $p=0.002$ & $p=0.006$ & $p=0.531$ \\
\hline \multirow{2}{*}{$\mathrm{L} \times \mathrm{Y}$} & $F=7.3$ & $F=14.2$ & $F=11.0$ & $F=12.2$ & $F=1.2$ \\
& $p<0.001$ & $p<0.001$ & $p<0.001$ & $p=0.006$ & $p=0.362$ \\
\hline
\end{tabular}

\subsection{SOC and SIC}

There were significant main effects (planting, year) for SOC from the surface $(20 \mathrm{~cm})$ sample but their interaction was also highly significant $(p<0.001$; Table 4). The planting $x$ year interaction was, in part, a consequence of an increase in SOC across years in the G-based treatments but not WP, and because the trend in SOC among the G treatments was not consistent across years (Figure 1A). One clear trend, however, is that the level of SOC was always lowest in the WP treatment $(p<0.05$; Figure 1A).
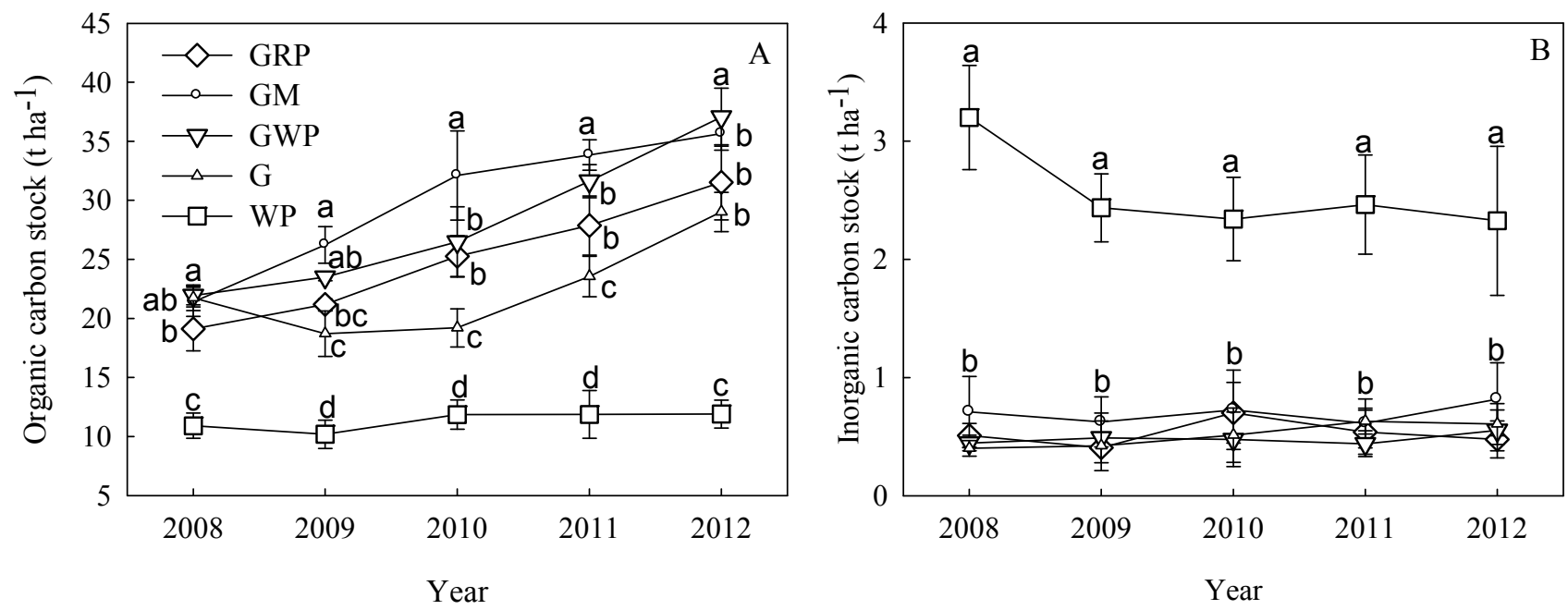

Figure 1. Soil organic carbon (A) and inorganic carbon (B) stocks in the $0-20 \mathrm{~cm}$ soil layer for five planting treatments, over the years 2008-2012. Vertical bars are the standard deviation $(n=3)$. Letters denote significant differences among treatments within a given year $(p<0.05)$. Abbreviations: GRP, Ginkgo + rapa + peanut; GM, Ginkgo + mulberry; GWP, Ginkgo + wheat + peanut; G, Ginkgo afforestation; and WP, wheat + peanut. Note differences between panels in the ordinate scale.

For SIC, only the planting treatment main effect was significant $(p<0.001$; Table 4$)$. In this case, SIC did not vary significantly across years $(p=0.990$; Table 4$)$ but stocks in the WP treatment were significantly greater than the G-based treatments in each year $(p<0.05$; Figure 1B). The latter did not differ from one another $(p>0.05)$. 
SOC stocks were 30-70 fold greater than SIC stocks in the G-based treatments (Figure 1A) but only 3-4-fold greater in the WP treatment (Figure 1B).

\subsection{C fractions}

For the six fractions, all planting and year main effects, and their interactions were highly significant ( $p<0.001$; Table 5). Values for POC, LOC, and WEOC tended to increase across years in all treatments except WP (Figure 2A,C, and E, respectively). Ginkgo afforestation (G) had the highest POC, LOC, and WEOC values $(p<0.05)$. The GM planting always had significantly higher OOC, $\mathrm{HOC}$, and HSOC, regardless of year (Figure 2B,D,F, respectively). There were no consistent trends in the $\mathrm{C}$ fractions of any other planting treatment. The $\mathrm{C}$ fractions associated with WP tended to be lower than the G-based plantings; the differences were significant in 25 of the 30 yearly comparisons (Figure 2).

Table 5. Two way repeated measures ANOVA results for planting treatment $(\mathrm{P})$ and year (Y), on the stock of soil organic carbon (SOC), soil inorganic carbon (SIC), particulate (POC), oxidizable (OOC), light fraction (LOC), heavy fraction (HOC), water extractable (WEOC) and hot water soluble (HSOC) organic carbon. Results were derived from the surface layer (to $20 \mathrm{~cm}$ ). Degrees of freedom for planting treatment and year were $F_{4,40}$, respectively, and $F_{16,40}$ for their interaction.

\begin{tabular}{ccccccccc}
\hline Source & SOC & SIC & POC & OOC & LOC & HOC & WEOC & HSOC \\
\hline \multirow{2}{*}{$\mathrm{P}$} & $F=162.3$ & $F=41.2$ & $F=118.8$ & $F=274.9$ & $F=70.1$ & $F=91.9$ & $F=136.5$ & $F=206.9$ \\
& $p<0.001$ & $p<0.001$ & $p<0.001$ & $p<0.001$ & $p<0.001$ & $p<0.001$ & $p<0.001$ & $p<0.001$ \\
\hline \multirow{2}{*}{$\mathrm{Y}$} & $F=61.3$ & $F=0.1$ & $F=54.9$ & $F=18.9$ & $F=14.6$ & $F=60.6$ & $F=74.5$ & $F=62.1$ \\
& $p<0.001$ & $p=0.990$ & $p<0.001$ & $p<0.001$ & $p<0.001$ & $p<0.001$ & $p<0.001$ & $p<0.001$ \\
\hline \multirow{2}{*}{$\mathrm{P} \times \mathrm{Y}$} & $F=6.5$ & $F=0.7$ & $F=17.2$ & $F=3.9$ & $F=4.1$ & $F=15.6$ & $F=13.3$ & $F=6.6$ \\
& $p<0.001$ & $p=0.786$ & $p<0.001$ & $p<0.001$ & $p<0.001$ & $p<0.001$ & $p<0.001$ & $p<0.001$ \\
\hline
\end{tabular}

In terms of the relative increase in fractions as compared to WP, the response in GRP and GWP (where crops were harvested semi-annually) was generally consistent for all fractions across the five measurement periods, reaching about a 2.5-fold increase by 2012 (Figure 2). The response in GM and $\mathrm{G}$ was more complex. OOC, HOC, and HSOC were always highest for GM, with the gap widening over time to between 3.5- and 4.5-fold greater than WP (Figure 2B,D,F, respectively). $\mathrm{G}$ increased relative to WP in the final two measurement periods to between 3.5- (POC), 4- (LOC), and 5-fold (WEOC) higher (Figure 2A,C,E, respectively). 

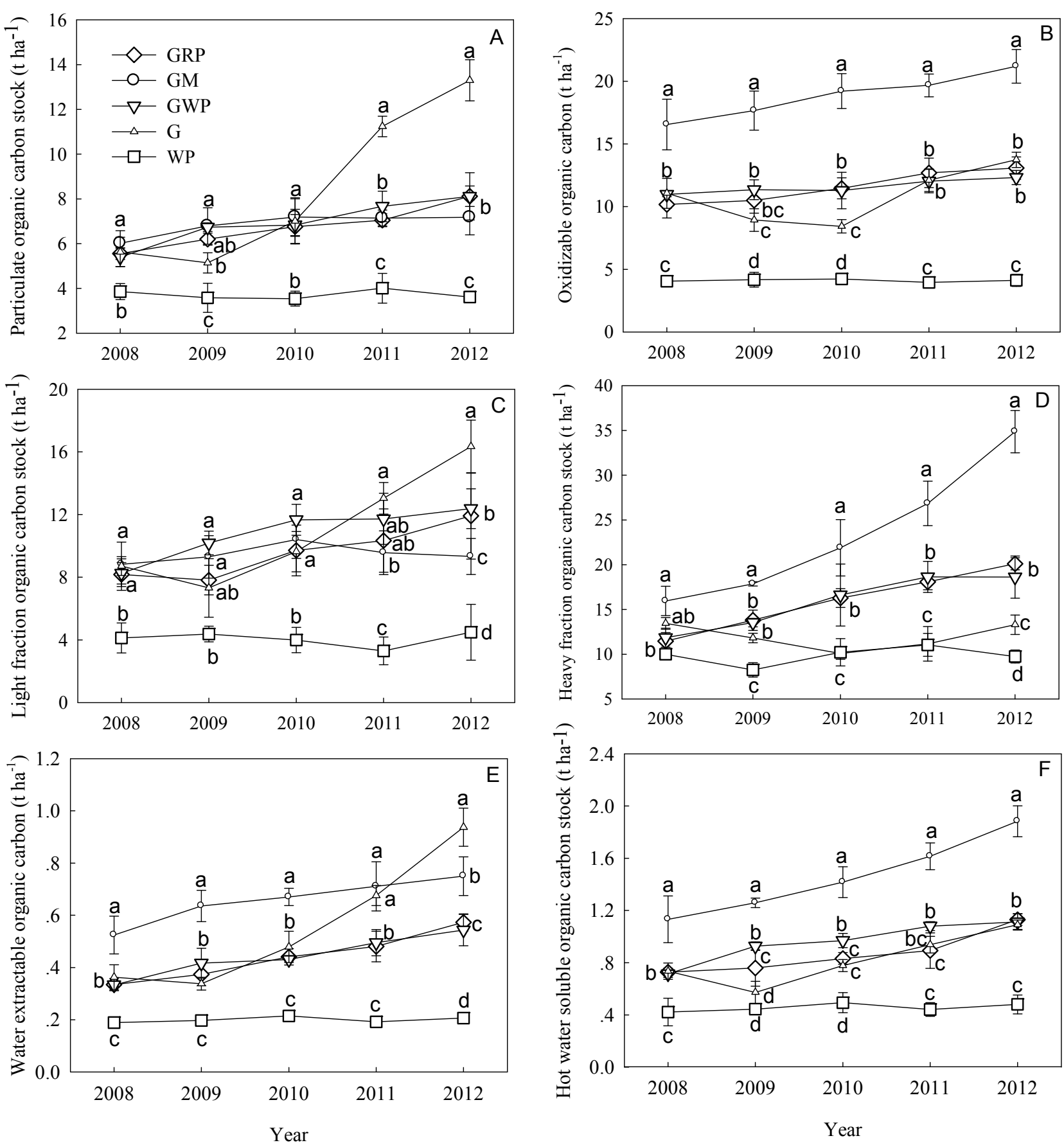

Figure 2. Particulate (A), oxidizable (B), light fraction (C), heavy fraction (D), water extractable (E) and hot water soluble (F) organic carbon stocks in the 0-20 cm soil layer for five planting treatments, over the years 2008-2012. Vertical bars are the standard deviation $(n=3)$. Letters denote significant differences among treatments within a given year $(p<0.05)$. Abbreviations: GRP, Ginkgo + rapa + peanut; GM, Ginkgo + mulberry; GWP, Ginkgo + wheat + peanut; G, Ginkgo afforestation; and WP, wheat + peanut. Note differences between panels in the ordinate scale. 


\section{Discussion}

\subsection{Storage}

TSC (80 cm, plus all layers separately) and SOC $(20 \mathrm{~cm})$ were significantly higher under agroforestry (GM, GWP and GRP) and afforestation (G) than monocropping (WP), across all years. This was likely due to inputs of C from autumn leaf-drop in the G-based systems [46], which were absent from WP. Singh et al. [47] reported a 33\%-83\% increase in SOC to depths of $45 \mathrm{~cm}$ relative to controls under Populus and Eucalyptus canopies intercropped with grasses, and which was attributed to differences in leaf litter inputs. The highest TSC stocks in the $80 \mathrm{~cm}$ sample were in GM. With both a taproot and lateral branches, Mulberry roots are large in diameter close to the main stem but then decrease rapidly in size forming dense fibrous mats $[48,49]$. Mulberry was harvested only for its leaves, and belowground growth and root turnover was likely additive across years, thereby providing an important addition to the $\mathrm{C}$ residues derived from the Ginkgo itself. TSC and SOC stocks both declined significantly with layer in all systems. A majority of root growth in Ginkgo and the associated plant species is restricted to shallow depths [30,50]. Hence, the decline was most likely because of an associated decrease in root biomass [30].

A critical influence on the soil organic $\mathrm{C}$ balance is the frequency and intensity of live biomass removal and/or its conversion to dead organic matter. Systems that are heavily cropped, for example, tend to have lower C stocks, particularly if intensive site preparation is also practiced [14]. In WP, a majority of plant biomass was removed semi-annually and the land then tilled to prepare for the subsequent crop. Tillage promotes organic matter decay while annual cropping also meant that root growth (and thus C input) was temporally restricted. As a result, the lowest TSC and SOC levels were always under WP. In the agroforestry systems, only a portion of total live biomass was removed in each cropping event (because the Ginkgo remained untouched), while under afforestation there were no removals. Benbi et al. [5] reported differences in SOC (to $15 \mathrm{~cm}$ ) among three cropping systems, one of which included agroforestry, but there were no significant differences in TSC. Agroforestry had been practiced for only 5-6 years in this system [5]. In our case, the treatments were in their fourth year, at the beginning of the experiment, and in their ninth year, at its conclusion. Given that TSC and SOC increased significantly over successive measurement years in the surface layer $(20 \mathrm{~cm})$ suggests that experiment duration is an important variable when attempting to assess treatment effects [29]. Species composition and growth conditions (soil and climate, for example) among the studies are additional considerations [12], as well as differences in experimental design [51].

Tree density may have been another key determinant of soil $\mathrm{C}$ accrual in our systems. Demessie et al. [52] measured soil $\mathrm{C}$ under traditional agroforestry in southern Ethiopia across a 50-year chronosequence. Although SOC stocks were higher than under corresponding farmlands the differences were not significant statistically. Very low tree densities (a maximum of 10 trees per ha) were utilized, however, as compared to our experiment where densities were at least 15-fold higher (156 stems per ha). Tree litter inputs would have been minimal in the Ethiopian system. In the poplar-based systems reported above, where SOC was enhanced under agroforestry, tree densities were also much greater, at 950 [5] and 350 stems per ha [29]. Tree cover is retained to improve crop production by providing shade and enhancing site nutrient and moisture balance [29]. To realize additional soil C storage 
benefits, however, sufficient densities must be established to ensure tree litter inputs counterbalance losses from crop harvesting [26].

SIC stocks to $20 \mathrm{~cm}$ were significantly greater in WP than GM, GWP, GRP, or G. SIC is mediated principally by chemical and physical processes $[53,54]$. In Chinese grassland soils, SIC stocks were more than seven-fold higher at $\mathrm{pH}>7$, as compared to lower $\mathrm{pH}$ values [54]. Wang and Cao [32] reported soil $\mathrm{pH}$ in the top $20 \mathrm{~cm}$ layer of a rapa-soybean cropping system at 7.9 but significantly lower values when Ginkgo and/or mulberry were present. The lower soil $\mathrm{pH}$ might have been due to increased soil nitrification $[32,55,56]$, which could explain the lower SIC values in the Ginkgo-based systems. SIC stocks were several orders of magnitude lower than SOC, however, and so the relative contribution of SIC to total C storage was low (cf. [53]).

From the perspective of converting agricultural land to agroforestry, or the use of afforestation, as a means for reducing atmospheric $\mathrm{CO}_{2}$ levels through enhanced storage, our results indicated that relative to WP, total soil $\mathrm{C}$ storage was at least doubled, increasing by $30 \mathrm{t} \mathrm{C} \cdot \mathrm{ha}^{-1}$, or more (to between 72 and $98 \mathrm{t} \mathrm{C} \cdot \mathrm{ha}^{-1}$; Table 3 ). These improvements increased across stand age (Table 2) though there were often significant interactions (Tables 2 and 4). A loss in soil organic C over the first decade following tree establishment is not uncommon [12,27] but did not seem to be a significant factor in our systems. One possible reason is that much of the land was only lightly cultivated. Disturbance was therefore restricted largely to the surface layer, which would have minimized any associated increase in organic matter decomposition [12]. Of note is also the fact the agroforestry systems generated storage benefits slightly greater than afforestation. This was probably because of enhanced litter inputs from the agricultural crops. Wang et al. [56] measured the SOC content in Phoebe bournei (Hemsley) Yang plantations located in subtropical regions of southeastern China. Though planting densities were higher (a minimum of $1000 \mathrm{stems} \cdot \mathrm{ha}^{-1}$ ), SOC stocks averaged 45 to $55 \mathrm{t} \cdot \mathrm{ha}^{-1}$, at rotation ages of 20 years and higher, values below those recorded here for total soil $\mathrm{C}$ at equivalent depths (63-83 t C $\cdot \mathrm{ha}^{-1}$; Table 3). As for long-term trends in storage, $\mathrm{C}$ can potentially continue to accrue for decades in our systems [57], assuming the soil is not heavily disturbed and the Ginkgo remains unharvested. Model simulations of Phoebe bournei [56] and Chinese fir (Cunninghamia lanceolata (Lamb.) Hook.) [58] plantations in subtropical China indicate that rotation lengths of less than 40 years could reverse gains in SOC. This suggests that the improvement in soil organic C storage reported here could be compromised if stands are replaced too soon. One reason for early replacement might be the decline in crop yields that occurs due to shading from the maturing Ginkgo overstory [30].

\subsection{Fractions}

Most of the fractions were significantly higher in the G-based systems versus WP. As with TSC and SOC, this was likely the result of additional organic matter inputs [41] from Ginkgo leaf deposition, and, possibly, the more extensive tillage that accompanied WP harvesting. In the case of mulberry, it tends to have high litter inputs [32], which appear to have favored OOC, HOC, and HSOC production. The biochemical properties of mulberry litter might also have been a factor in WEOC accumulation. In the first four measurement years, GM soil had the highest WEOC content. Wang and Cao [32] observed greater nutrient availability and soil enzyme activity associated with mulberry litter, as 
compared to other Ginkgo-based agroforestry and cropping systems. WEOC is likely the most labile and mobile form of SOC and its abundance has been correlated with litter quality [17].

With afforestation $(\mathrm{G})$, stocks of POC and LOC rose sharply over the last two measurement periods, from 3.5- to 4-fold higher, respectively, relative to WP; these fractions remained relatively constant in the other systems. Competitive interference is an important factor in reducing Ginkgo production under agroforestry [30], which in turn could result in lower litter inputs and, hence, stocks. LOC is considered a favorable substrate for decomposition [59], and the size of the LOC pool may be at least partly dependent on residue inputs [36]. One explanation for the trend in LOC (and POC) then is that, due to a lack of crop competition, productivity and corresponding litter inputs in G may have gradually exceeded production in GM, GRP, and GWP. Alternatively, there may have been a change in the decomposer community associated with G that reduced LOC degradation. POC and LOC are also both sensitive to soil disturbance (see [15] and [39], respectively), which was minimal in G as compared to the other systems.

The presence of Ginkgo appeared to be key to higher levels of HOC in GRP, GWP, and GM as compared to the WP. Under G, however, HOC showed little or no significant difference from WP. HOC exists as organo-mineral complexes, the latter of which can be depleted through cultivation [60]. That $\mathrm{G}$ had the least soil disturbance should thus have favored HOC retention [61]. It thus appears that the combination of litter inputs from both the Gingko and the crops favored HOC accumulation.

\section{Conclusions}

The agroforestry systems were highly effective at restoring organic C stocks in soils that were previously under agricultural production but there were also benefits simply in converting to Ginkgo alone (afforestation). In the nine years following tree establishment, these systems accumulated increasingly greater total and SOC stocks compared to monocropping, the latter of which showed no change. Labile $\mathrm{C}$ fractions were sensitive indicators of the change in cultivation practices. Their overall increase associated with the addition of Ginkgo suggested an improvement in soil quality.

\section{Acknowledgments}

This study was supported by a grant from the "Research and demonstration of oriented cultivation technology in Ginkgo plantations" (2012BAD21B04) program, provided by the Science and Technology Department of China, and the "Planting technologies in medical plantation of Ginkgo and camphor trees" (20120460102) program, provided by the State Forestry Bureau, Jiangsu. The quality of the manuscript was improved significantly by the generous contribution of three anonymous reviewers.

\section{Author Contributions}

Guibin Wang conceived of the study, and conducted field and lab measurements, and data analysis. Clive Welham, Chaonian Feng, Lei Chen, and Fuliang Cao developed the conceptual ideas and participated in study design. Clive Welham and Lei Chen contributed to data analysis. Guibin Wang and Clive Welham wrote the manuscript. 


\section{Conflicts of Interest}

The authors declare no conflict of interest.

\section{References}

1. IPCC (Intergovernmental Panel on Climate Change). Climate Change: The Physical Science Basis. Contribution of Working Group I to the Fifth Assessment Report of the Intergovernmental Panel on Climate Change; Cambridge University Press: Cambridge, UK, 2013.

2. Schmidt, W.I.; Torn, M.S.; Abiven, S.; Dittmar, T.; Guggenberger, G.; Janssens, I.A.; Kleber, M.; Kogel-Knabner, I.; Lehmann, J.; Manning, D.A.C.; et al. Persistence of soil organic matter as an ecosystem property. Nature 2011, 478, 49-56.

3. Smith, P.; Fang, C.; Dawson, J.; Moncrieff, J. Impact of global warming on soil organic carbon. Adv. Agron. 2008, 97, 1-43.

4. Le Quéré, C.; Andres, R.J.; Boden, T.; Conway, T.; Houghton, R.A.; House, J.I.; Marland, G.; Peters, G.P.; van der Werf, G.; Ahlström, A.; et al. The global $\mathrm{CO}_{2}$ budget 1959-2011. Earth Syst. Sci. Data 2013, 5, 165-185.

5. Benbi, D.K.; Brar, K.; Toor, A.S.; Singh, P.; Singh, H. Soil carbon pools under poplar-based agroforestry, ricewheat, and maize-wheat cropping systems in semi-arid India. Nutr. Cycl. Agroecosyst. 2012, 92, 107-118.

6. Turrión, M.-B.; Schneider, K.; Gallardo, J.F. Carbon accumulation in Umbrisols under Quercus pyrenaica forests: Effects of bedrock and annual precipitation. Catena 2009, 79, 1-8.

7. Davidson, E.A.; Janssens, I.A. Temperature sensitivity of soil carbon decomposition and feedbacks to climate change. Nature 2006, 440, 165-173.

8. Mahdavi, K.; Choupanian, A.; Gheytouri, M.; Mahdavi, M. Effect of physiographic factors on soil carbon sequestration in Kermanshah (Iran). Int. J. For. Soil Eros. 2012, 2, 159-162.

9. Jobbágy, E.G.; Jackson, R.B. The vertical distribution of soil organic carbon and its relation to climate and vegetation. Ecol. Appl. 2000, 10, 423-436.

10. Poeplau, C.; Don, A.; Vesterdal, L.; Leifeld, J.; Van Wesemael, B.; Schumacher, J.; Gensior, A. Temporal dynamics of soil organic carbon after land-use change in the temperate zone-Carbon response functions as a model approach. Glob. Chang. Biol. 2011, 17, 2415-2427.

11. Don, A.; Schumacher, J.; Freibauer, A. Impact of tropical land-use change on soil organic carbon stocks-A meta-analysis. Glob. Chang. Biol. 2011. 17, 1658-1670.

12. Lorenz, K.; Lal, R. Soil organic carbon sequestration in agroforestry systems. A review. Agron. Sustain. Dev. 2014, 34, 443-454.

13. Santore, R.C.; Driscoll, C.T.; Aloi, M. A model of soil organic matter: Its function in temperate forest soil development. In Carbon Forms and Functions in Forest Soils; McFee, W.W., Kelly, J.M., Eds.; Soil Science Society of America: Madison, WI, USA, 1995; pp. 275-298.

14. Sherrod, L.A.; Peterson, G.A.; Westfall, D.G.; Ahuja, L.R. Soil organic carbon pools after 12 years in no-till dryland agroecosystems. Soil Sci. Soc. Am. J. 2005, 67, 1533-1543.

15. Chan, K.Y. Soil particulate organic carbon under different land use and management. Soil Use Manag. 2001, 17, 217-221. 
16. Bremer, E.; Jansen, H.H.; Johnston, A.M. Sensitivity of total, light fraction and mineralizable organic matter to management practices in a Lethbridge soil. Can. J. Soil Sci. 1994, 74, 131-138.

17. Boyer, J.N.; Groffmann, P.M. Bioavailability of water-extractable organic carbon fractions in forest and agricultural soil profiles. Soil Biol. Biochem. 1996, 28, 783-790.

18. Degryze, S.; Six, J.; Paustian, K.; Morris, S.J.; Paul, E.A.; Merck, R. Soil organic carbon pool changes following land-use conversions. Glob. Chang. Biol. 2004, 10, 1120-1113.

19. Hsiung, W. Ecosystem engineering and modern agroforestry. In Agroforestry: Research and Practice; Hsiung, W., Chandler, P.F., Eds.; China Forestry Publishing House: Beijing, China, 1996; pp. 1-10.

20. Nair, P.K.R.; Kumar, B.M.; Nair, V.D. Agroforestry as a strategy for carbon sequestration. J. Plant Nutr. Soil Sci. 2009, 172, 10-23.

21. Nair, P.K.R.; Nair, V.D.; Kumar, B.M.; Haile, S.G. Soil carbon sequestration in tropical agroforestry systems: A feasibility appraisal. Environ. Sci. Policy 2009, 12, 1099-1111.

22. IPCC (Intergovernmental Panel on Climate Change). Land Use, Land-use Change, and Forestry: A Special Report of the Intergovernmental Panel on Climate Change; Cambridge University Press: Cambridge, UK, 2000.

23. Kumar, B.M.; Nair, P.K.R. Carbon Sequestration Potential of Agroforestry Systems: Opportunities and Challenges; Springer: New York, NY, USA, 2011.

24. Blair, G.J.; Lefroy, R.D.B.; Lisle, L. Soil carbon fractions based on their degree of oxidation, and the development of a carbon management index for agricultural systems. Aust. J. Agric. Res. 1995, 46, 1459-1466.

25. Skjemstad, J.O.; Swift, R.S.; McGowan, J.A. Comparison of the particulate organic carbon and permanganate oxidation methods for estimating labile soil organic carbon. Soil Res. 2006, 44, 255-263.

26. Vesterdal, L.; Clarke, N.; Sigurdsson, B.D.; Gundersen, P. Do tree species influence soil carbon stocks in temperate and boreal forests? For. Ecol. Manag. 2013, 309, 4-18.

27. Li, D.; Niu, S.; Luo, Y. Global patterns of the dynamics of soil carbon and nitrogen stocks following afforestation: A meta-analysis. New Phytol. 2012, 195, 172-181, doi:10.1111/j.14698137.2012.04150.x.

28. Nair, P.K.R. Agroforestry systems and environmental quality: Introduction. J. Environ. Qual. 2011, 40, 784-790.

29. Gupta, N.; Kukal, S.S.; Bawa, S.S.; Dhaliwal, G.S. Soil organic carbon and aggregation under poplar based agroforestry system in relation to tree age and soil type. Agrofor. Syst. 2009, 76, 2735.

30. Cao, F. Ecological Basis for Ginkgo Agroforestry Systems. Ph.D. Thesis, Department of Forest Sciences, The University of British Columbia, Vancouver, BC, Canada, 2004.

31. $\mathrm{Xu}, \mathrm{J}$. Evaluation of growth benefits in different comprehensive management patterns of Ginkgo and citrus. Nonwood For. Res. 2006, 24, 32-34. (In Chinese)

32. Wang, G.; Cao, F. Integrated evaluation of soil fertility in Ginkgo (Ginkgo biloba L.) agroforestry systems in Jiangsu, China. Agrofor. Syst. 2011, 83, 89-100. 
33. Schumacher, B.A. Methods for the Determination of Total Organic Carbon (TOC) in Soil and Sediments; Report NCEA-C- 1282, EMASC-001; Ecological Risk Assessment Support Center, Office of Research and Development, US Environmental Protection Agency: Las Vegas, NV, USA, 2002.

34. Yuan, K.L. Study of organomineral complex in soil: The primary study of oxidization stability of humus in organomineral complex in soil. Acta Pedol. Sin. 1963, 11, 286-293.

35. Barreto, P.A.B.; Gama-Rodrigues, E.F.; Gama-Rodrigues, A.C.; Fontes, A.G.; Polidoro, J.C.; Moço, M.K.S.; Machado, R.C.R.; Baligar, V.C. Distribution of oxidizable organic C fractions in soils under cacao agroforestry systems in Southern Bahia, Brazil. Agrofor. Syst. 2011, 81, 213-220.

36. Gregorich, E.G.; Janzen, H.H. Storage of soil carbon in the light fraction and macro organic matter. In Advances in Soil Science: Structure and Organic Matter Storage in Agricultural Soils; Carter, M.R., Stewart, B.A., Eds.; CRC Press: Boca Raton, FL, USA, 1996; pp. 167-190.

37. Hassink, J. Density fractions of soil macroorganic matter and microbial biomass as predictors of $\mathrm{C}$ and N mineralization. Soil Biol. Biochem. 1995, 27, 1099-1108.

38. Kay, B.D. Soil structure and organic carbon, a review. In Soil Processes and the Carbon Cycle; Lal, R., Kimble, J.M., Follett, R.F., Stewart, B.A., Eds.; CRC Press: Boca Raton, FL, USA, 1998; pp. 169-197.

39. Tan, Z.; Lal, R.; Owens, L.; Izaurralde, R.C. Distribution of light and heavy fractions of soil organic carbon as related to land use and tillage practice. Soil Tillage Res. 2007, 92, 53-59.

40. Wander, M.M.; Traina, S.J. Organic matter fractions from organically and conventionally managed soils. I. Carbon and nitrogen distribution. Soil Sci. Soc. Am. J. 1996, 60, 1081-1087.

41. Janzen, H.H.; Campbell, C.A.; Brandt, S.A.; Lafond, G.P.; Townley-Smith, L. Light-fraction organic-matter in soils from long-term crop rotations. Soil Sci. Soc. Am. J. 1992, 56, 1799-1806.

42. Lu, X.; Fan, J.; Yan, Y.; Wang, X. Soil water soluble organic carbon under three alpine grassland types in Northern Tibet, China. Afr. J. Agric. Res. 2011, 6, 2066-2071.

43. Schulz, E. Influence of site conditions and management on different soil organic matter (SOM) pools. Arch. Agron. Soil Sci. 2004, 50, 33-47.

44. McGill, W.B.; Cannon, K.B.; Robertson, J.A.; Cook, F.D. Dynamics of soil microbial biomass and water-soluble organic $\mathrm{C}$ in Breton $\mathrm{L}$ after 50 years of cropping to two rotations. Can. J. Soil Sci. 1986, 66, 1-19.

45. Ghani, A.; Dexter, M.; Perrott, K.W. Hot-water extractable carbon in soils: A sensitive measurement for determining impacts of fertilisation, grazing and cultivation. Soil Biol. Biochem. 2003, 35, 1231-1243.

46. Chen, L. The Effects of Carbon Stocks and Soil Carbon Cycle in Ginkgo Agroforestry Systems. Ph.D. Thesis, Nanjing Forestry University, Nanjing, China, 2013.

47. Singh, K.; Chauhan, H.S.; Rajput, D.K.; Singh, D.V. Report of a 60-month study on litter production, changes in soil chemical properties and productivity under poplar ( $P$. deltoides) and Eucalyptus hybrid interplanted with aromatic grasses. Agrofor. Syst. 1989, 9, 37-45.

48. Bunger, M.T.; Thomson, H.J. Root development as a factor in the success or failure of windbreak trees in the southern high plains. J. For. 1938, 36, 790-803.

49. Farrar, J.L. Trees of the Northern United States and Canada; Blackwell Publishing: Ames, IA, USA, 1995. 
50. Jackson, R.B.; Canadell, J.; Ehleringer, J.R.; Mooney, H.A.; Sala, O.E.; Schulze, E.D. A global analysis of root distributions for terrestrial biomes. Oecologia 1996, 108, 389-411.

51. Cohen, J.C. Statistical Power Analysis. Curr. Dir. Psych. Sci. 1992, 1, 98-101.

52. Demessie, A.; Singh, B.R.; Lal, R. Soil carbon and nitrogen stocks under chronosequence of arm and traditional agroforestry land uses in Gambo District, Southern Ethiopia. Nutr. Cycl. Agroecosyst. 2013, 95, 365-375.

53. Wu, H.; Guo, Z.; Gao, Q.; Peng, C. Distribution of soil inorganic carbon storage and its changes due to agricultural land use activity in China. Agric. Ecosyst. Environ. 2009, 129, 413-421.

54. Shi, Y.; Baumann, F.; Ma, Y.; Song, C.; Kühn, P.; Scholten, T.; He, J.S. Organic and inorganic carbon in the topsoil of the Mongolian and Tibetan grasslands: Pattern, control and implications. Biogeosciences 2012, 9, 2287-2299.

55. Montagnini, F.; Sancho, F. Net nitrogen mineralization in soils under six indigenous tree species, an abandoned pasture and a secondary forest in the Atlantic lowlands of Costa Rica. Plant Soil 1994, 162, 117-124.

56. Wang, W.; Wei, X.; Liao, W.; Blanco, J.A.; Liu, Y.; Liu, S.; Liu, G.; Zhang, L.; Guo, X.; Guo, S. Evaluation of the effects of forest management strategies on carbon sequestration in evergreen broad-leaved (Phoebe bournei) plantation forests using FORECAST ecosystem model. For. Ecol. Manag. 2012, 300, 21-32.

57. Watson, R.T.; Noble, I.R.; Bolin, B.; Ravindranath, N.H.; Verardo, J.D.; Dokken, D.J. Land Use, Land-Use Change and Forestry: IPCC Special Report; Cambridge University Press: Cambridge, UK, 2000.

58. Bi, J.; Blanco, J.A.; Seely, B.; Kimmins, J.P.; Ding, Y.; Welham, C. Yield decline in Chinese-fir plantations: A simulation investigation with implications for model complexity. Can. J. For. Res. 2007, 37, 1615-1630.

59. Neff, J.C.; Townsend, A.R.; Gleixner, G.; Lehman, S.J.; Turnbull, J.; Bowman, W.D. Variable effects of nitrogen additions on the stability and turnover of soil carbon. Nature 2002, 419, 915917.

60. Jastrow, J.D. Soil aggregate formation and the accrual of particulate and mineral-associated organic matter. Soil Biol. Biochem. 1996, 28, 665-676.

61. Song, B.; Niu, S.; Zhang, Z.; Yang, H.; Li, L.; Wan, S. Light and Heavy Fractions of Soil Organic Matter in Response to Climate Warming and Increased Precipitation in a Temperate Steppe. PLoS ONE 2012, 7, e33217, doi:10.1371/journal.pone.0033217.

(C) 2015 by the authors; licensee MDPI, Basel, Switzerland. This article is an open access article distributed under the terms and conditions of the Creative Commons Attribution license (http://creativecommons.org/licenses/by/4.0/). 